Recibido: 13/09/2021 --- Aceptado: 10/11/2021 --- Publicado: 10/12/2021

\title{
TRATO DEL TELEDIARIO PÚBLICO ESPAÑOL A TEMAS Y LÍDERES POLÍTICOS (2014-2021)
}

\section{TREATMENT TO ISSUES AND POLITICAL LEADERS IN SPANISH PUBLIC NEWSCAST (2014-2021)}

(D) (8) Noel Bandera López ${ }^{1}$ : Universitat de València. España. noel.bandera-lopez@uv.es

\section{Cómo citar el artículo:}

Bandera López, N. (2021). Trato del telediario público a temas y líderes políticos (2014-2021). Revista de Comunicación de la SEECI, 54, 19-39. http://doi.org/10.15198/seeci.2021.54.e736

Financiación: Investigación realizada bajo el disfrute de una beca FPU del Gobierno de España para la formación de profesorado universitario.

\section{RESUMEN}

Ante la ausencia o retraso e incompletitud de registros de lo emitido en TV pública, se ofrece un estudio único, por su alcance (desde 2014 a 2021) y su novedoso método, sobre el Telediario de La 1 de Televisión Española. Se usa la herramienta Verba de la Fundación Civio, cuyo afán por la transparencia es presentado en la introducción, además de tratar la influencia de los medios en partidos políticos y agenda. El objetivo principal es evaluar dos tipos de elementos: 30 nombres de líderes políticos y 30 expresiones con incidencia política (los 15 principales problemas citados por la ciudadanía en el último CIS y otros 15 vinculados). El modelo se centra en las palabras pronunciadas y faltarían otros elementos audiovisuales del Telediario. Los resultados muestran un trato favorable a PSOE, PP y Ciudadanos y desfavorable a los partidos de izquierdas, los soberanistas y Vox. En cuanto a las palabras seleccionadas, se abusa de algunas, como "consenso" y sobre todo "polémica", mientras lo social recibe menor atención que la expresada por la ciudadanía y lo relacionado con el sistema político o económico aparece aún menos. No existe proporcionalidad ni en la relevancia concedida a los problemas del CIS ni a los partidos de acuerdo con sus votos. Futuras investigaciones podrían aplicar la metodología afinándola para no contabilizar menciones no pertinentes.

\footnotetext{
${ }^{1}$ Noel Bandera López: investigador predoctoral con contrato FPU, Instituto de Derechos Humanos, València. 3 licenciaturas/grados (Derecho, Ciencias Políticas, Sociología), 2 másteres (Filosofía contemporánea, Comunicación, Cultura, Sociedad y Política) y 5 artículos de autoría individual publicados.
} 
PALABRAS CLAVE: Telediario, televisión, información, noticias, partido político, comunicación política, servicio público

\section{ABSTRACT}

Considering the absence or delay and incompleteness in the registration of what is shown in public TV, it is offered an unique study, because of its reach (from 2014 to 2021) and new method, about news programme from the first channel of the National Spanish Television. It is used Civio's Foundation tool: Verba, whose transparency-seeking is presented in the introduction, besides treating media influence in political parties and agenda. There are two groups of elements that are assessed: 30 names of political leaders and 30 terms with political incidence (the 15 most common issues to citizens, according to the last CIS analysis issued and 15 others linked). This model centres in pronounced terms, lacking other audiovisual elements from the news programme. Results show a favourable treatment to PSOE, PP and Ciudadanos and unfavourable to political parties on the left, nationalists parties and Vox. From the selected words, it is found that some terms, such as "consensus" and especially "controversy", are highly used whilst social issues receive less importance than the expressed by citizens and terms related to the political or economic system are barely mentioned. There is no proportionality nor in the relevance granted to the issues appearing on the CIS nor to the political parties according to its electoral results. Future research could use the method polishing it to not count irrelevant mentions.

KEY WORDS: Television news, television, information, news, political parties, political communication, public utilities.

\section{TRATAMENTO DO TELEDIARIO PÚBLICO ESPANHOL SOBRE QUESTÕES POLÍTICAS E LÍDERES (2014-2021)}

\section{RESUMO}

Dada a ausência ou atraso e incompletude dos registros do que foi veiculado na TV pública, oferece-se um estudo inédito, por sua abrangência (de 2014 a 2021) e seu método inovador, no Telediario de La 1 de Televisión Española. É utilizada a ferramenta Verba da Fundação Civio, cujo desejo de transparência é apresentado na introdução, além de tratar da influência da mídia nos partidos políticos e na agenda. O objetivo principal é avaliar dois tipos de elementos: 30 nomes de líderes políticos e 30 expressões com impacto político (os 15 principais problemas citados pelo público no último CIS e outros 15 relacionados). O modelo se concentra nas palavras faladas e outros elementos audiovisuais do noticiário estariam faltando. Os resultados mostram um tratamento favorável ao PSOE, PP e Ciudadanos e desfavorável aos partidos de esquerda, soberanistas e Vox. Quanto às palavras selecionadas, algumas são abusadas, como "consenso" e sobretudo "polêmica", enquanto o aspecto social recebe menos atenção do que o expresso pelos cidadãos e o que está relacionado ao sistema político ou econômico aparece ainda menos. Não há proporcionalidade nem 
na relevância atribuída aos problemas do CIS nem aos partidos segundo os seus votos. Pesquisas futuras podem aplicar a metodologia ajustando-a de modo a não contar menções irrelevantes.

PALAVRAS-CHAVE: Noticiário, televisão, informação, notícias, partido político, comunicação política, serviço público

\section{INTRODUCCIÓN}

Careciendo España de un Consejo Audiovisual de ámbito estatal, como sí lo hay en el resto de países de la Unión Europea (Consejo Audiovisual de Andalucía, 2013) y en varias autonomías, y teniendo en cuenta las limitaciones y el retraso del informe sobre pluralismo en TVE de la Comisión Nacional de los Mercados y la Competencia (en 2021 se publicó el correspondiente a 2018), se ha entendido necesario investigar el trato que da el servicio público a temas y líderes políticos.

Los temas tratados, así como el modo de hacerlo, constituyen un elemento central de todo medio de comunicación, partido político o actor social. Hasta el punto de que la teoria de la agenda setting es una de las más relevantes en el último medio siglo y son múltiples sus derivadas y posibles recorridos.

Los partidos confrontan en un escenario marcado por la agenda pública construida. Y ahí tienen especial protagonismo los medios de comunicación, siendo la televisión aún, con diferencia, el que reúne una mayor audiencia y cuya influencia es más determinante.

En cuanto a la duración del impacto de los medios en la opinión pública, MacKuen (1981) fijó un período de entre 1 y 9 meses, dependiendo de la materia; este autor situaba, en orden creciente en cuanto a la durabilidad, los siguientes temas: energía ( 1 mes), derechos civiles (4 meses), Vietnam, inflación, medio ambiente y crímenes (de 6 a 9 meses).

Para analizar los efectos a largo plazo de la agenda setting puede consultarse la investigación de Watt et al. (1993), que, aun siendo de hace varias décadas, se refiere a la televisión y aporta un estudio longitudinal con duración infrecuente: más de 4 años. La fórmula usada para medir la prominencia de cada noticia premiaba las largas, las cercanas al inicio del programa y las que incluían video.

Respecto a las menciones a políticos o partidos, Silver (2015) o Stray (2016) han registrado robustas correlaciones entre la atención mediática dada a un político y la estimación media de voto en las encuestas, en su caso sobre todo en relación a las primarias en EE.UU.

En concreto con ejemplos como el de Trump y otros políticos similares en otros países, una pregunta que cobró mayor protagonismo fue la de "¿qué afecta más 
para determinar el apoyo electoral: la cantidad de atención mediática o la presentación positiva o negativa en esa cobertura?".

La cantidad de atención mediática recibida es el elemento fundamental, según autores como Silver, por delante de la valoración positiva: "the interesting thing, as we've pointed out before, is that a candidate can potentially gain in the polls in the short term by increasing his media coverage, even if he potentially hurts his favorability rating. Trump seems to realize this" (Silver, 2015).

La Fundación Civio es la creadora de la herramienta que se utiliza en esta investigación y es impulsora de proyectos para mejorar el acceso ciudadano a la política. Se trata de una organización española sin ánimo de lucro y con más de 1.000 socios que, según se presenta en su página web, desde fines de 2011 "vigila a los poderes públicos, informa a todos los ciudadanos y presiona para lograr una transparencia real y eficaz en las instituciones".

Su objetivo es "lograr un libre acceso a la información que estas generan, saber cómo se toman las decisiones, contar con políticas públicas basadas en la evidencia, lograr que el sector público rinda cuentas y facilitar la acción y la participación ciudadana. Y las palancas que usamos para lograr estos cambios son el periodismo y la innovación".

Un equipo de 9 personas cuya misión es acabar con la opacidad en los asuntos públicos. Una de sus iniciativas es Verba, un registro de todas las palabras pronunciadas en telediarios de La 1 de Televisión Española en horario de mediodía (15:00 horas) y noche (21:00 horas) desde el año 2014 (las excepciones son dos: una en junio de 2018 y otro en el 10 de mayo de 2019 porque no están publicados los subtítulos).

Verba se basa en una aplicación web de código abierto resultado de una beca de la Google Digital News Initiative. Su buscador permite hallar todas las apariciones de cualquier palabra o frase y verlas en su contexto.

Aunque relativamente joven, Civio cuenta ya con numerosas apariciones en artículos científicos. Así, Casero-Ripollés y López-Meri (2015) expusieron 4 casos de estudio y Civio fue uno de ellos (los otros, el británico mySociety, el estadounidense Sunlight Foundation y el chileno Ciudadano inteligente). Entre los hitos de Civio señalaron encabezar el Ranking de Innovación Periodística 2014, elaborado por el Grupo de Investigación de la Comunicación (GICOV) de la Universidad Miguel Hernández (UMH) de Elche (2015: 111).

En un TFG dirigido por el mismo Casero-Ripollés, Carsí (2016) se centra en Civio y Poletika.org para analizar sus webs, actividad en redes sociales, documentos y manifiestos y repercusión en medios digitales. Civio destaca en la transparencia en la difusión de información en su web pero no en la interactividad online (2016: 17). 
Por entonces, Civio contaba con 9.500 seguidores en Twitter y 6.800 "me gusta" en Facebook (2016: 18-19). A 23 de agosto de 2021, las cifras eran 46.100 y 10.400, respectivamente. Cadena SER, La Vanguardia y El Mundo son 3 medios que difundieron el trabajo de la fundación en sus inicios (2016: 20).

Su empeño en la transparencia fue destacado ya por Alonso González y García Orta (2016) -o luego por Cortés del Álamo et al., 2018-. También en 2016, fue uno de los 16 medios y entidades seleccionados por Ferreras Rodríguez por practicar periodismo de datos.

También podemos citar la inclusión de un reportaje de Civio en el análisis de Sánchez Calero y Mancinas-Chávez (2017) o los estudios de Capoano (2018) y Valero-Pastor y Carvajal (2019), que en ambos casos entrevistan a la Fundación Civio para analizar sus procesos de trabajo e innovación.

En el primer caso se incluyen otras tres organizaciones periodísticas españolas (Vocento, El Confidencial y WeblogsSL) y en el segundo otra organización brasileña (Agência Pública). Capoano (2018: 88) destaca la interdisciplinariedad de los investigadores de Civio y la combinación de formatos en su narrativa (infografías, aplicaciones, informes largos...).

Por su parte, Valero-Pastor y Carvajal indagan en la transferencia de conocimiento y en el caso de Civio, su representante Miguel Ángel Gavilanes señala que la vía más fructífera es la conversación informal (2019: 1167), aunque también admite que la menor institucionalización de ciertos procesos provoca pérdidas de información (2019: 1166).

Con un enfoque similar al presentado en la presente investigación, Matarín (2020) codifica las 257 menciones que hubo a las palabras "inmigración" o "inmigrantes" en los informativos de TVE en los primeros 8 meses de pandemia del coronavirus:

"Por frecuencia de aparición destaca Donald Trump, presidente de Estados Unidos (EE.UU), siendo el más citado (17,5\%), seguido por Santiago Abascal" (Matarín, 2020 , p. 297). Las referencias a Vox suponen un $12,7 \%$ de las realizadas a actores 0 instituciones políticas.

Señala asimismo la baja aparición del resto de partidos, salvo cargos nombrados por el PSOE. Varias veces se habla de si hay o no acuerdos entre los socios de Gobierno, pero no se hace hincapié en las concreciones. De este modo, se observa que en las noticias no se vinculan los temas que afectan a la inmigración con el discurso de los partidos ubicados ideológicamente a la izquierda.

A excepción de lo que sucede en el caso de Vox, las alusiones no se centran en los partidos ni en los cargos orgánicos de sus miembros, trasladando así el mensaje ideológico de cada uno de ellos, sino que se realizan haciendo referencia a la representación de cargos institucionales, como sucede por ejemplo con las 
menciones al Gobierno de España (7,90\%); al Gobierno de Canarias (4,80\%); al Relator de la ONU (4,80\%); Delegación del Gobierno (3,20\%) entre otros.

Es relevante señalar que las referencias al presidente del Gobierno de España son tan solo de un $1,60 \%$. Porcentaje comparativamente muy inferior respecto al presidente de EE.UU.

El trato privilegiado recibido por Vox y el contraste con el maltrato a las formaciones de izquierdas se corrobora además por otras investigaciones, como la de Estevez et al. (2020), en la que se aprecia cómo en las elecciones generales de noviembre de 2019 en España, entre las menciones a partidos políticos de ámbito estatal, Vox recibió mucha más atención en 13 principales periódicos online que la que le correspondía entonces por número de votos o escaños (24).

Mientras, Unidas Podemos, con 42 escaños, quedó reducido a entre un $6 \%$ y un $12 \%$ cada día de campaña y con menor presencia en los días decisivos, los previos a las elecciones. A la inversa, el porcentaje de apariciones de Vox crece en los días más influyentes, rondando el $25 \%$ del total en el último día de campaña (en el que alcanza su máximo) y en el antepenúltimo.

También usa la herramienta Verba de Civio para el análisis de la cobertura periodística Vicente (2020), que utiliza Verba para comprobar y cuestionar la prácticamente nula relevancia concedida a algunos temas, en este caso de divulgación científica y en particular los relacionados con la tabla periódica.

Otra demostración crítica de la agenda del Telediario público procede de ArévaloSalinas et al. (2021), en concreto para su cuarto apartado, comprobando cuántas menciones hubo en telediarios de La1 a palabras relacionadas con inmigración.

\section{OBJETIVOS}

Se procede a la investigación sobre el trato a temas y líderes políticos en el Telediario de La1 como evaluación del grado de pluralismo y periodismo practicados en una cadena de televisión de ámbito estatal, siendo la TV aún el principal medio de información en cuanto a audiencias. Con mayor justificación por tres razones: primero, por tratarse de un servicio público; segundo, por su relevancia, al constituir el resumen oficial de noticias del día y al emitir La1 los telediarios más vistos de RTVE; y tercero, porque desde que La2Noticias está suspendida (12 de marzo de 2020), La1 emite los únicos informativos de televisión públicos y de ámbito estatal, más allá de canales temáticos.

La estructura del artículo se despliega en una presentación de los temas en el marco teórico, incluyendo la herramienta usada (el buscador Verba) y la fundación creadora (Civio); una explicación metodológica de qué temas y líderes se han seleccionado y cómo, así como de las dos partes del análisis; la exposición de resultados y las conclusiones. Las dos hipótesis a verificar son: 
A. Los líderes políticos reciben un número de menciones proporcional a sus resultados electorales

B. Los temas recibirán un número de menciones proporcional a la relevancia que les da la ciudadanía en las encuestas del CIS y a la importancia que tienen para el sistema político y económico vigente

\section{METODOLOGÍA}

Se analizan 60 elementos: 30 correspondientes a temas y 30 sobre líderes políticos. En el primer grupo, se toman los 15 problemas más citados por los entrevistados en el CIS en el último estudio disponible que incluya las preguntas sobre cuáles son los principales problemes del país (julio 2021) y otras 15 palabras o expresiones relacionadas, una por cada uno de esos 15 temas principales.

En cuanto a los personajes políticos, se toma a dos portavoces de cada partido con al menos 2 escaños, a ellos se suman un representante de la confluencia Navarra Suma y otro del BNG (el partido con más votos entre los que tienen un escaño) y por último 4 antiguos líderes.

Los datos se extraen de la herramienta Verba a fecha 28 de agosto de 2021. El procedimiento con cada uno de los 60 temas y nombres estudiados se compone de tres partes: una cuantitativa y otra cualitativa. El análisis de contenido del punto 2 se justifica con que "este procedimiento no solo requiere de un análisis descriptivo, sino que se complementa con el análisis interpretativo" (Bernete, 2013: 236).

1) En primer lugar, se ofrece el número de menciones que recibe cada elemento en telediarios públicos de mediodía y noche desde 2014 hasta el 28 de agosto de 2021.

2) El segundo componente consiste en una reflexión sobre el trato que se da a cada tema y político. Se consideran en especial variables como la relevancia dada a las noticias en las que se menciona a ese tema o político y su enfoque positivo, neutral o negativo. Ambas son variables seguidas en la investigación de Matarín (2020) y antes en otras, como la de Teso (2014). Para cada objeto de estudio se realiza un análisis de al menos las últimas 20 menciones recibidas.

Para todo el proceso se usa la herramienta Verba de la plataforma Civio. Las dos limitaciones a reseñar son: por un lado, la dificultad para limpiar la búsqueda de usos de la palabra que sean diferentes al principal; por otro, no se realiza un análisis estadístico complejo, al preferir el modelo planteado.

Los 30 representantes políticos seleccionados respetan escrupulosamente la igualdad de género (15 mujeres y 15 hombres). Para los partidos no estatales, se toma un segundo portavoz de otro ámbito territorial. Son los siguientes:

- Pedro Sánchez y Nadia Calviño por el PSOE

- Pablo Casado y Díaz Ayuso por el PP

- Santiago Abascal y Macarena Olona por Vox 
- Alberto Garzón e Isa Serra por Unidas Podemos

- Yolanda Díaz y Ada Colau por las confluencias asociadas a UP

- Gabriel Rufián y Carme Forcadell por ERC

- Inés Arrimadas e Ignacio Aguado por Ciudadanos

- Carles Puigdemont y Laura Borràs por Junts

- Aitor Esteban e Izaskun Bilbao por PNV

- Mertxe Aizpurúa y Arnaldo Otegi por EH Bildu

- IIñigo Errejón y Joan Baldoví por Más País y Compromís

- Mireia Vehí y Dolors Sabater por CUP

- Sergio Sayas por Navarra Suma y Ana Pontón por BNG

- Por último, como ex líderes se selecciona a Felipe González, Mariano Rajoy, Pablo Iglesias y Rosa Díez

Los 30 temas escogidos son (entre paréntesis, el correspondiente problema citado en el CIS de julio de 2021, pregunta 16, por orden de menciones):

- Crisis y capitalismo ("La crisis económica, los problemas de índole económica")

- Paro y reforma laboral ("El paro")

- Coronavirus y reforma fiscal ("Los peligros para la salud: COVID-19. El coronavirus.

- Falta de recursos suficientes para hacer frente a la pandemia")

- Clase política y regeneración ("El mal comportamiento de los/as políticos/as")

- Régimen y Transición a la democracia ("Los problemas políticos en general")

- Sanidad y atención primaria ("La sanidad")

- Consenso y polémica ("La falta de acuerdos, unidad y capacidad de colaboración.

- Situación e inestabilidad política")

- Inversión social y desahucios ("Los problemas de índole social")

- Conciencia de clase y cultura política ("Poca conciencia ciudadana (falta de civismo, de sentido espíritu cívico)")

- Programa y oposición ("El Gobierno y partidos o políticos/as concretos/as")

- Cumplimiento del acuerdo y pacto de coalición ("Lo que hacen los partidos políticos")

- Precariedad y huelga ("Los problemas relacionados con la calidad del empleo")

- Referéndum ilegal y soberanía ("La independencia de Cataluña")

- Sistema educativo y ciencia ("La educación")

- Corrupción y fraude ("La corrupción y el fraude")

Uno de los trabajos citados que usan el mismo buscador es el de Vicente (2020), en principio bastante específico (sobre la tabla periódica), y que no amplía las variables más allá de conocer el número de menciones al tema en el telediario. Sí ofrece una lista de posibles noticias relacionadas que no aparecieron (2020: 123), lo cual constituye una sugerente vía para futuros desarrollos de investigaciones similares.

En lo que respecta al artículo de Matarín (2020), focaliza la atención en las menciones a únicamente dos términos, descartando otros por contener referencias a temas no relevantes para la investigación (2020: 293), una problemática también 
enfrentada en el presente artículo y con difícil arreglo exhaustivo, dado que en esta ocasión los resultados incluidos son 29.203 para los líderes políticos y aproximadamente el doble para los temas seleccionados.

Igualmente, al centrarse en un único tema (inmigración, como el anterior) y unos días muy concretos (17-23 de junio de 2018), la metodología empleada por ArévaloSalinas et al. (2021) es más proclive a un análisis detallado. Uno que, además de las menciones a determinadas palabras usando el buscador Verba, incluye aspectos como la duración de la noticia, sus fuentes y decisiones en la selección de temas (2021: 17).

\section{DISCUSIÓN}

Los resultados cuantitativos se presentan en la Tabla 1 y en la Tabla 2. PSOE, PP y Ciudadanos reciben gran atención, mientras son infravalorados los partidos de izquierdas, los soberanistas y Vox. Existen grandes diferencias entre Pedro Sánchez (1.675 menciones desde 2020) y Pablo Casado (736) y entre este y Santiago Abascal (161).

Una parte se explica por las mayores referencias de otros al presidente del Gobierno pero en ambos casos la diferencia entre el primer partido y el segundo y entre el segundo y el tercero es mucho mayor a la realmente existente en número de votos o escaños.

Tabla 1. Número de menciones a políticos en los Telediarios de La1

\begin{tabular}{|c|c|c|c|}
\hline Polític@ & $\begin{array}{c}\text { Menciones } \\
\text { desde 2014 } \\
\text { (desde 2020) }\end{array}$ & Polític@ & $\begin{array}{c}\text { Menciones } \\
\text { desde 2014 } \\
\text { (desde 2020) }\end{array}$ \\
\hline Pedro Sánchez & $10.347(1.675)$ & Nadia Calviño & $155(103)$ \\
\hline Pablo Casado & $2.080(736)$ & Díaz Ayuso & $539(413)$ \\
\hline Santiago Abascal & $354(161)$ & Macarena Olona & $5(2)$ \\
\hline Alberto Garzón & $346(38)$ & Isa Serra & $14(9)$ \\
\hline Yolanda Díaz & $118(110)$ & Ada Colau & $614(35)$ \\
\hline Gabriel Rufián & $130(36)$ & Carme Forcadell & $267(31)$ \\
\hline Inés Arrimadas & $527(218)$ & Ignacio Aguado & $91(48)$ \\
\hline Carles Puigdemont & $1.928(93)$ & Laura Borràs & $27(19)$ \\
\hline Aitor Esteban & $68(10)$ & Izaskun Bilbao & $5(0)$ \\
\hline Mertxe Aizpurúa & $1(1)$ & Arnaldo Otegi & $193(25)$ \\
\hline Íñigo Errejón & $287(10)$ & Joan Baldoví & $26(3)$ \\
\hline Mireia Vehí & $1(1)$ & Dolors Sabater & $11(6)$ \\
\hline Sergio Sayas & $1(1)$ & Ana Pontón & $19(9)$ \\
\hline Felipe González & $527(63)$ & Mariano Rajoy & $6.474(143)$ \\
\hline Pablo Iglesias & $3.917(773)$ & Rosa Díez & $131(3)$ \\
\hline
\end{tabular}

Fuente: Verba/Civio

Inés Arrimadas, líder de un partido con 10 escaños, multiplica por 6 desde 2020 las menciones al portavoz de ERC, que tiene más escaños, e igualmente multiplica 
por 6 las menciones al líder de IU y ministro de Consumo. Arrimadas incluso duplica las menciones a la ministra de Trabajo (que además era ya vicepresidenta en parte del período analizado). El nombre "Arrimadas" tiene un total de 858 menciones desde 2014, mientras que la portavoz de EH Bildu, Mertxe Aizpurúa (que también tuvo cargos territoriales relevantes antes de llegar al Congreso) solo es mencionada una vez (y para recibir una dura crítica).

El trato privilegiado a Ciudadanos se ve también en el caso de Ignacio Aguado (cuya formación pasó a ser extraparlamentaria en Madrid en 2021): tuvo 48 menciones desde 2020, en tanto que otros vicepresidentes autonómicos no recibieron ni una. Díaz Ayuso, presidenta de la tercera comunidad autónoma por población, multiplica por 12 las menciones a Ada Colau, alcaldesa de la segunda ciudad de España.

En las menciones a Pedro Sánchez hay bastantes que consisten en críticas de la oposición. De las últimas 20, 7 son críticas de la oposición, 2 son peticiones de sus socios de Gobierno y 1 es sobre aplausos y abucheos recibidos. Salvo al dar la estimación de voto del CIS, las menciones a Pablo Casado son ejerciendo su labor de oposición, en positivo o neutrales, incluso cuando se trata de un caso de corrupción: "El presidente del Partido Popular, Pablo Casado, se desvincula de Villarejo y recuerda que el partido ya adoptó medidas disciplinarias con Fernández Díaz".

En el caso de Nadia Calviño, recibe escasas alusiones para ser vicepresidenta, suelen ser positivas y destaca la frecuencia con la que aparece enfrentada a sus socios de coalición. Díaz Ayuso, por ejemplo, cuadruplica las apariciones de Calviño, en línea con el protagonismo de Madrid en estos telediarios: 68.094 menciones totales, frente a las 8.827 de Andalucía (y considerando dos matices: que Andalucía tiene más población que Madrid y que en la búsqueda de este último se incluyen las alusiones a la ciudad y a la comunidad autónoma).

Por otra parte, sorprende la escasa atención a una portavoz importante de Vox, Macarena Olona, al igual que sucede con su líder, Santiago Abascal. 3 de las 5 menciones a Olona son sobre su expulsión de la Diputación Permanente del Congreso "después de que intentara forzar un debate sobre Cataluña que no estaba en el orden del día". Con Abascal hay numerosas referencias a disturbios en lugares donde realiza mítines.

Entre las 20 últimas menciones a Alberto Garzón, 8 son del PP pidiendo su cese, en otras 4 se usan los verbos "acusar" e "insistir", en 1 se presentan en negativo las aspiracions electorales de su candidatura, en otra se presenta como contradictorio que salude al rey y en la más reciente se le critica por una campaña para reducir el consumo de carne, como recomiendan la OMS, la UE y multitud de organismes científicos e Internacionales.

La mitad de las 14 menciones a Isa Serra (Podemos) se refieren a su causa judicial por intentar parar el desahucio de un discapacitado en 2014. Después de convertirse en portavoz de su formación, sólo aparece 5 veces y 3 de ellas son sobre 
su imputación. Las 6 últimas menciones a Yolanda Díaz se enmarcan en diferencias entre ella o su coalición y su socio, el PSOE.

Con Ada Colau hay no pocos mensajes relacionados con violencia en las calles. En otros, se usan formas verbales como "boicotear" o "ha cargado contra...", además de relacionarla con un posible caso de corrupción con la Plataforma de Afectados por la Hipoteca.

Para Gabriel Rufián, portavoz de ERC en el Congreso, las menciones son bajas para ser el sexto grupo estatal en número de escaños y normalmente decisivo para lograr mayoría. Prácticamente todas las referencias a Carme Forcadell son sobre su situación penitenciaria. Entre las alusiones más recientes a Inés Arrimadas, con frecuencia se refieren al partido y su situación de crisis interna tras varios pésimos resultados.

El trato a Ignacio Aguado, de Ciudadanos, es privilegiado en cuanto a número de apariciones para un portavoz autonómico y también en el enfoque recibido. Incluso es entrevistado en directo en el Telediario y es anunciado en los titulares del mismo (1 de octubre de 2020, 21 horas).

Con Carles Puigdemont, en cambio, se emplea la expresión "huidos" o "huyeron" en 4 ocasiones consecutivas. "Fugado" también. Las menciones suelen ser sobre cuestiones judiciales y/o con enfoque negativo (él supone el "principal escollo", "obstáculos", "cerrará el paso"...).

Algo similar se ve con su compañera Laura Borràs: "advierte", "ha aprovechado su encuentro con el rey para reprocharle", "ha llamado desleal", "castración química", "barrera de alianzas constitucionalistas", "dice ahora", "no ha acudido hoy al desfile". 7 de las 23 últimas alusiones a Borràs son sobre una causa judicial abierta contra ella, acusándola de malversación y fraude fiscal por la adjudicación de unos contratos.

Las referencias a Aitor Esteban son neutrales o positivas, salvo quizá una en la que se dice que niega la despedida a Espinosa de los Monteros (Vox). Todas las menciones a su compañera eurodiputada Izaskun Bilbao fueron en 2014, ninguna en 2019 (cuando también se presentó y logró escaño). Además del desprecio a la portavoz de Bildu (que sólo aparece una vez y es duramente criticada), el Telediario público dedica 10 de sus últimas 20 menciones a Arnaldo Otegi a hablar de causas judiciales contra él.

Por su parte, Íñigo Errejón tiene un número relevante de apariciones pero no desde 2020 sino antes, en especial en septiembre de 2019 (lanzamiento de Más País) y finales de 2016 y principios de 2017 (procesos internos en Podemos). Joan Baldoví (Compromís), Ana Pontón (BNG) y Dolors Sabater (CUP) son líderes territoriales de izquierdas que reciben un número de menciones similar, algunas más Baldoví y menos la portavoz de la CUP. 
De los 11 resultados que recibe esta última, 2 son críticas de otro político, 3 son en el contexto de los disturbios en Catalunya en febrero de 2021 y las demás son presentaciones rápidas. La única mención a su compañera Mireia Vehí fue al saludar a otra diputada. Lo mismo ocurre con el cabeza de lista de Navarra Suma, Sergio Sayas, cuya única aparición es al ser abrazado por Pablo Casado.

En cuanto a Ana Pontón (BNG), las últimas 4 alusiones a su nombre (y las únicas desde las elecciones gallegas) se referían a las diligencias abiertas por la Fiscalía de la Audiencia Nacional por posibles injurias al rey cuando el rey emérito se fue de España a Emiratos Árabes Unidos.

Terminando con los ex-políticos analizados, Felipe González es nombrado fundamentalmente en tres tipos de noticias: cuando opina sobre la actualidad, cuando se relata algun hecho histórico y cuando se halaga o critica su gestión, en especial ante la petición de formación de una comisión de investigación al publicarse un informe sobre su implicación en el terrorismo de los GAL.

En el caso de Mariano Rajoy, sus menciones son superiores, al ser el presidente inmediatamente anterior al actual. Todas las 20 últimas referencias a Rajoy son sobre investigaciones en casos de corrupción, salvo un par de críticas a su gestión.

Respecto a Pablo Iglesias, casi todas sus menciones recientes aluden a su abandono de la política, siendo su sucesión el tema con más apariciones. En su tiempo como vicepresidente se observa el abuso de palabras en negativo, como "choque", "polémica", "enfado", "exigido", "acusa", "disturbios", "arremetiendo", "aluvión de críticas", "oleada de críticas"...

Además, son constantes las censuras de la oposición, incluidas frases en las que el periodista da por hecho que Iglesias alienta disturbios: "El PP pide la destitución de Pablo Iglesias por alentar los disturbios", repetida. Esto contrasta con el criterio general de incluir palabras que aclaran que es opinión del emisor.

Por último, las escasas alusiones a Rosa Díez son en especial a su apoyo al PP y su convocatoria para protestar contra la política del Gobierno sobre Catalunya.

Tabla 2. Número de menciones en los Telediarios de La1 a los temas más citados en el CIS (Tema A) y a palabras relacionadas (Tema B)

\begin{tabular}{|c|c|c|c|}
\hline Tema A & $\begin{array}{c}\text { Menciones } \\
\text { desde 2014 } \\
\text { (desde 2020) }\end{array}$ & Tema B & $\begin{array}{c}\text { Menciones } \\
\text { desde 2014 } \\
\text { (desde 2020) }\end{array}$ \\
\hline Crisis & $10.358(3.404)$ & Capitalismo & $66(10)$ \\
\hline Paro & $4.095(843)$ & Reforma laboral & $673(119)$ \\
\hline Coronavirus & $7.789(7.778)$ & Reforma fiscal & $434(56)$ \\
\hline Clase política & $253(37)$ & Regeneración & $517(13)$ \\
\hline Régimen & $2.614(302)$ & $\begin{array}{c}\text { Transición a la } \\
\text { democracia }\end{array}$ & $33(4)$ \\
\hline Sanidad & $6.602(4.326)$ & Atención primaria & $538(375)$ \\
\hline
\end{tabular}




\begin{tabular}{|c|c|c|c|}
\hline Consenso & $1.429(338)$ & Polémica & $4.248(910)$ \\
\hline Inversión social & $29(11)$ & Desahucios & $259(87)$ \\
\hline Conciencia de clase & $0(0)$ & Cultura política & $67(9)$ \\
\hline Programa electoral & $293(8)$ & Oposición & $7.316(1.264)$ \\
\hline $\begin{array}{c}\text { Cumplimiento del } \\
\text { acuerdo }\end{array}$ & $10(1)$ & Pacto de coalición & $72(15)$ \\
\hline Precariedad & $447(108)$ & Huelga & $3.256(240)$ \\
\hline Referéndum ilegal & $524(51)$ & Soberanía & $814(73)$ \\
\hline Sistema educativo & $147(25)$ & Ciencia & $1.305(332)$ \\
\hline Corrupción & $4.335(343)$ & Fraude & $2.621(410)$ \\
\hline
\end{tabular}

Fuente: Verba/Civio

Destacar la escasísima atención concedida a los temas "capitalismo", siendo el sistema económico vigente y en plena crisis, "cumplimiento del acuerdo", "pacto de coalición", "sistema educativo", "desahucios", "cultura política", "regeneración", "transición a la democracia"...

Y la nula aparición de la expresión "conciencia de clase". "Sanidad" se dispara durante la pandemia pero no dispuso de tanta cobertura en los 6 años anteriores. La palabra "polémica", por ejemplo, tuvo más de 1.000 menciones más que la palabra "sanidad" entre 2014 y 2019.

El término "crisis" es asociado en los telediarios a un amplio abanico de temas, aunque en las últimas semanas analizadas sobresale su uso constante para referirse a la situación en Afganistán. Antes de ello sí era la más frecuente la alusión a la crisis del coronavirus.

En un plazo de 2 años (entre agosto de 2019 y agosto de 2021), sólo se encuentran 5 comentarios críticos con el capitalismo (o 6, a lo sumo), ninguno se encuentra en titulares $y$, de hecho, ninguno aparece en los primeros 16 minutos del informativo, siendo lo más común a partir de la media hora.

Además, varias de las menciones son en países extranjeros y otras en el ámbito de la poesía, e incluso se tilda de "ideológico" un texto que habla del "capitalismo salvaje que nos hemos autoimpuesto", y eso que esa autoimposición nunca ha sido tal, nunca se ha preguntado expresamente por el sistema económico.

Llama la atención que en los 3 últimos meses (junio-agosto 2021), cuando se registraron bajadas históricas de desempleo, sólo 34 frases contuvieran la palabra "paro" ( $y$ en este caso, como en muchos otros, hay que descontar algunos resultados que no son sobre el tema tratado).

Es más, ninguno de esos 34 abrió el Telediario como noticia principal, a pesar de los datos históricos y a pesar de que durante muchos años los españoles han situado esta como su principal preocupación. Si comparamos con los mismos meses de 2019, hallamos más del triple de resultados (116). 
También es ilustrativo el caso de la expresión "reforma laboral", pues derogarla era una de las principales promesas de Pedro Sánchez y, sin embargo, desde que fue investido por primera vez las menciones en telediarios son reducidas e incluso hay meses enteros en los que no aparece.

Sobre "reforma fiscal", los últimos 5 resultados se refieren a la propuesta del Banco de España, bastantes de los resultados se refieren a Colombia y no a España y sólo 1 de las 20 menciones (la menos reciente) detalla algo qué impuestos cambiarían, algo básico.

Para "coronavirus", lo más interesante es ver la evolución de sus apariciones desde que irrumpiera en marzo de 2020 (aunque anteriormente ya hubo menciones):

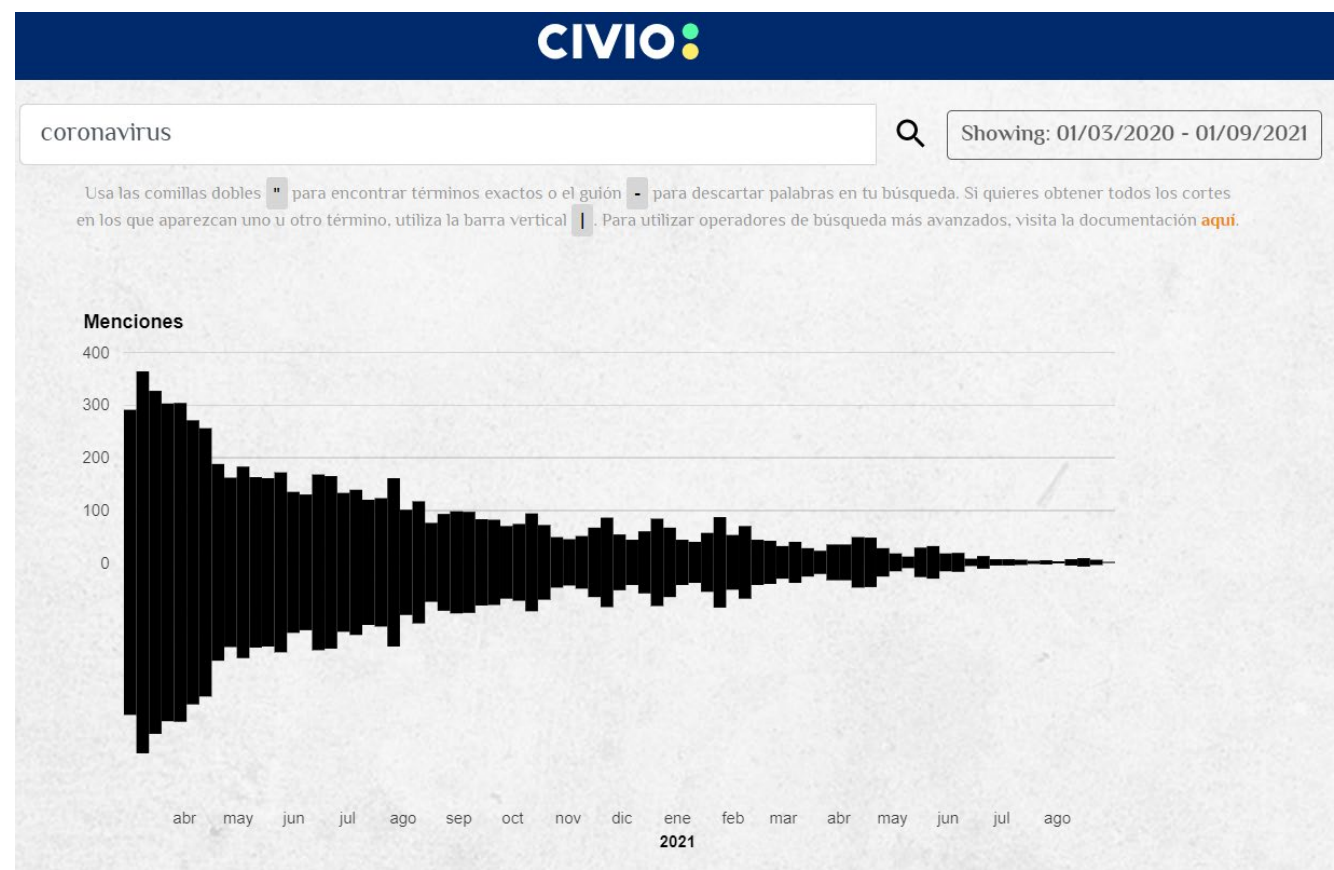

Figura 1. Evolución de menciones a "coronavirus" en Telediarios de La1 Fuente: Verba/Civio

Se trata de un decrecimiento lineal continuo, sobresaliendo las escasas menciones en los últimos meses y la enorme diferencia con los primeros. Con la expresión "clase política" hallamos 7 menciones recientes que se referían a otros países. Con la palabra "Régimen" ocurre algo similar pero más acusado: 14 de 20 referencias son a regímenes extranjeros, 2 son en otro sentido y 4 son palabras del PP para criticar al Gobierno y un supuesto "cambio de Régimen".

Por tanto, sólo un $20 \%$ se refieren al Régimen político español y un $0 \%$ son críticas al mismo. Con "regeneración", sólo hay 5 referencias en el último año y medio que se refieran a regeneración política. Desde 2017, sólo aparecen 4 menciones respecto a España al escribir "transición a la democracia" y las 4 son positivas sobre la Transición y sus protagonistas. 
Aparte de en la pandemia del coronavirus, las menciones a la sanidad sólo destacan en otoño de 2014, por la crisis del ébola. En cuanto a la Atención Primaria, se le da muy poca relevancia, salvo a finales de 2018 e inicios de 2019, con las protestas en varias comunidades autónomas por falta de recursos, y el Telediario se centró en especial en criticar la situación en Catalunya.

La insistencia en usar las palabras "consenso" y "polémica" son sintomáticas del enfoque ideológico. La primera, "consenso", por ser definitoria del relato de la Transición y desde entonces como ideal político para mantener el statu quo en las cuestiones fundamentales.

Y la segunda, "polémica", para reducir el debate a cuestiones superficiales y emocionales, trasladar una imagen de que todas las opciones políticas son iguales y como distracción de los temas importantes. Que las menciones a "polémica" tripliquen incluso las numerosas menciones a "consenso" muestra la determinación del Telediario por trasladar esa aproximación controversial a la política.

La expresión "inversión social" como dinero público invertido en temas sociales no aparece ninguna vez desde 2015 (cuando se usa para resumir una intervención de Pablo Casado y otra de Pedro Sánchez) y sólo en 2 ocasiones de 2020 hay frases muy cercanas: "inversión pública social" el 27/10/2020 (15 horas, minuto 10) en referencia a los Presupuestos Generales de 2021 e "inversión en lo social" el 23/07/2020 (21 horas, minuto 21) sobre una temática más concreta. En otras ocasiones se usa el sinónimo "gasto social", más frecuente y con una connotación algo distinta a "inversión social".

Salvo para anunciar la prórroga de la suspensión de desahucios de personas vulnerables (aunque siguieron produciéndose), la palabra "desahucios" no aparece durante más de 3 meses, a partir del 25 de mayo, que es aludida para explicar que "los antisistema" (refiriéndose a la CUP) presionan a ERC para cumplir en materia de Vivienda.

"Cultura política", por su parte, sólo aparece 11 veces en casi 8 años (varias generales, varias vinculadas a Podemos, 2 al PSOE o PSC y 1 a Venezuela), pues las demás registradas son frases en las que aparecen cercanas las palabras "cultura" y "política".

Buscando "Programa electoral" encontramos que el Telediario público renuncia a explicar cuál es el programa de partidos gobernantes, qué prometieron. Desde 2020 (es decir, en 1 año y 8 meses), las escasas referencias a programa electoral son a países extranjeros (EE.UU., Italia e Irlanda).

Se encuentra también una en el marco de un juicio a la Mesa del Parlament (por tramitar iniciativas parlamentarias, entre ellas algunas contempladas en programa electoral) y otra es sobre un programa común "polémico" de 20 años atrás, 
comentado en la necrológica sobre Paco Frutos (candidato de IU en 2000). Aparte sólo hay una apelación genérica y otra en una obra de ficción.

Estos datos quedan corroborados por los de "cumplimiento del acuerdo": en 2020 hay una mención respecto a un acuerdo UE-Reino Unido, en 2019 un par de ellas previas a acuerdos y una manifestación policial reclamando al Gobierno lo acordado.

Debemos remontarnos a 2018 para hallar una alusión al análisis del cumplimiento de un acuerdo ("Ciudadanos celebra este viernes en Málaga un comité ejecutivo nacional al que su líder regional, Juan Marín, llevará un informe sobre el nivel de cumplimiento del acuerdo de legislatura con el PSOE", 05/09/2018); del contenido se dice que "Ciudadanos acusa a Susana Díaz de no cumplir puntos de ese acuerdo como el cambio de la ley electoral o la eliminación de los aforamientos".

En la misma línea, "pacto de coalición" dispone de poco desarrollo en los Telediarios de TVE. En los 8 meses de 2021 registrados, sólo hay 2 citas de UP sobre lo estipulado en el pacto de coalición en un punto (poner techo a las subidas abusivas del alquiler de vivienda) y una frase en la que se indica que "Después de semanas de discrepancias públicas en el gobierno de coalición, hoy hemos escuchado al presidente Sánchez decir que está satisfecho del pacto con Unidas Podemos" (23/02/2021, 21 horas, minuto 8).

Por su parte, la palabra "oposición" es usada con frecuencia y mayoritariamente para referirse a la oposición en el Congreso de los Diputados, que es la parte activa de las noticias, salvo cuando es Pedro Sánchez o alguien del PSOE quienes interpelan a los grupos de la oposición.

Respecto a la aparición de la palabra "precariedad" puede ser relevante señalar que en los 1620 días del mandato de Rajoy cuyos telediarios están registrados, se mencionó la precariedad 0,13 veces por día, mientras que, desde que Yolanda Díaz es ministra de Trabajo, la frecuencia aumenta un $33,4 \%$.

Si bien la pandemia cubre casi todo el tiempo del Gobierno de coalición y eso aumentó la precariedad, el número de contratos indefinidos en agosto de 2020 era superior al que había en agosto de 2012, 2013, 2014 y 2015, primeros años de la reforma laboral del PP. Y la cifra en agosto de 2021 es superior además a la de 2016 у 2017.

Distinta es la distribución de la palabra "huelga", pues desde 2020 las semanas con mayores picos de menciones se quedan en 12 ó 13, mientras que en 2019 se sobrepasa esa cota con frecuencia y se llega a 70 menciones en 2 semanas diferentes. En 2018 hay 3 semanas que baten ese registro. En los años anteriores no hay datos tan elevados pero sí mayores que los de 2020.

La insistencia en usar la expresión "referéndum ilegal" (524 veces) contrasta con "referéndum acordado" (19 veces). En "soberanía", se habla de otros países o de 
Gibraltar, Sahara, Ceuta o Melilla, salvo una alusión de UP a que la jefatura de Estado no está sometida a la soberanía popular.

En 8 meses de 2021, "sistema educativo" sólo aparece 4 veces: 2 sobre otros países y 2 críticas del PP al Gobierno. En 2020 hay muchas alusiones a los efectos de la pandemia y a la nueva ley de educación: son fundamentalmente críticas de la oposición o de defensores de la educación concertada o posicionamientos del PSOE o alguno del PNV, siendo difícil hallar opiniones de izquierdas.

\section{CIVIO:}

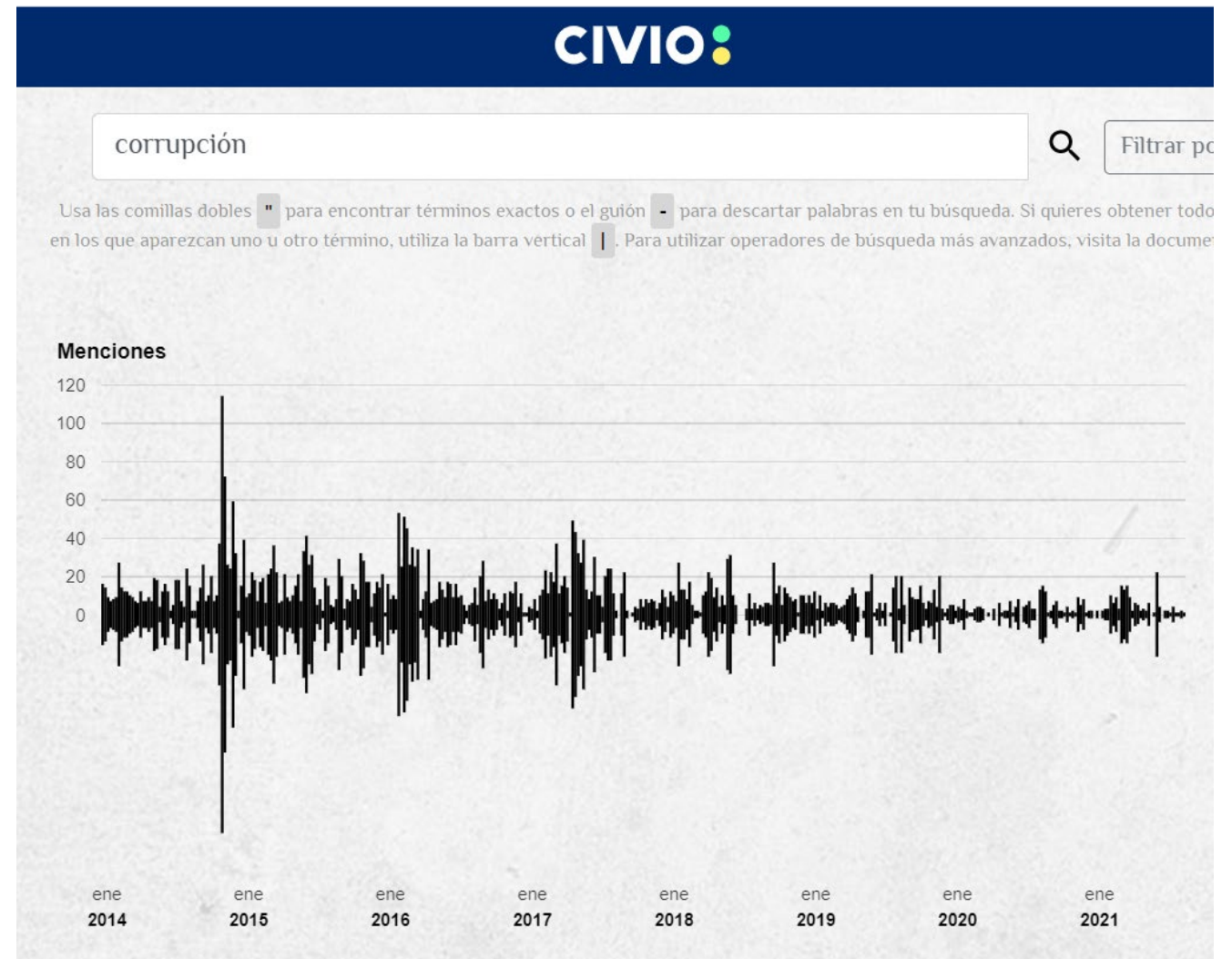

Figura 2. Evolución de menciones a "corrupción" en Telediarios de La1

Fuente: Verba/Civio

\section{CONCLUSIONES}

La presente investigación busca ampliar los estudios sobre la televisión pública y sobre las diferencias entre la agenda mediática y las preocupaciones ciudadanas con una metodología novedosa y con componentes cuantitativo y cualitativo. Se usa la 
herramienta Verba de la fundación Civio, que dispone ya de una larga cobertura en materias de transparencia.

En cuanto al trato a líderes políticos en telediarios, se observa un déficit de atención a formaciones de izquierdas, a soberanistas y a Vox, mientras que partidos como PP y Ciudadanos son ampliamente beneficiados tanto cuantitativa como cualitativamente y el PSOE se erige en el centro de la actualidad política en una proporción mucho mayor al voto recibido.

Así, destacan las 1.675 menciones a Pedro Sánchez desde 2020 y el hecho de que Inés Arrimadas multiplique por 6 las menciones al líder de IU y ministro de Consumo (Alberto Garzón) y también a Gabriel Rufián, cuya formación supera a Ciudadanos en escaños y es más relevante en la formación de mayorías.

Las alusiones a la líder de Ciudadanos también duplican las de la ministra de Trabajo y vicepresidenta segunda del Gobierno en parte del período analizado, Yolanda Díaz. Los partidos territoriales, mayoritariamente de izquierdas, sufren tanto por el escaso número de apariciones como por el trato negativo. También Junts es perjudicado, mientras el trato al PNV es neutral.

La agenda desplegada revela las tendencias conservadoras del Telediario, empezando por la poca atención concedida a temas como "desahucios", "sistema educativo" o "precariedad", que, a pesar de ser uno de los problemas ciudadanos más citados en encuestas del CIS, recibe menos menciones que "referéndum ilegal".

Se abusa de palabras con fuerte y oculta carga ideológica, como "consenso" y sobre todo "polémica". Otras, como "clase política" o en especial "Régimen" se usan bastante para referirse a otros países. Los términos relacionados con el sistema económico, como "capitalismo" o "conciencia de clase", aparecen muy poco o nada, respectivamente.

Algo similar ocurre, a pesar de su relevancia, con "reforma laboral", "reforma fiscal", "inversión social" y las que aluden al sistema político, como la citada "Régimen", "regeneración" o "transición a la democracia". Por su parte, las menciones a "coronavirus" decrecen a un ritmo muy claro.

En cuanto a los partidos políticos, los resultados son congruentes con lo concluido para la prensa en Estevez et al. (2020), salvo porque en ese caso Vox salía beneficiado y aquí no. También con Matarín (2020) existe esta divergencia.

La distribución de las menciones ofrece indicios relevantes a favor de la correlación entre atención mediática y voto recibido, en línea con Silver (2015) y Stray (2016) y quedando en segundo término -aunque también importante- el trato positivo o negativo de esas menciones.

Las hipótesis no se cumplen: no se respeta la proporcionalidad ni de los resultados electorales en la asignación de atención en los telediarios a líderes ni de las 
respuestas ciudadanas sobre los problemas del país ni en el caso de que atendamos a la importancia de los temas para el sistema político y económico.

Con los datos tomados, es el segundo punto citado el que se sitúa más cerca de cumplirse, pues 15 de las 30 palabras analizadas reciben más de 100 menciones desde 2020, mientras el tercero es el que arroja resultados más opuestos: a mayor relevancia sistémica, menor cobertura.

La principal aportación del estudio es el balance actualizado y de largo alcance temporal y temático del enfoque del Telediario público, en especial careciendo España de un Consejo Audiovisual como sí existe en otros estados de la UE y considerando la incompletitud y el gran retraso con el que se publica el informe sobre TVE de la Comisión Nacional de los Mercados y la Competencia.

Suponen dos limitaciones del estudio no emplear modelos estadísticos avanzados y que el análisis se refiere a palabras pronunciadas en telediarios pero no incluye otros elementos, sobre todo las imágenes emitidas en un medio propiamente audiovisual. Esto puede hallarse en estudios como el de Sánchez Castillo (2018), sobre entrevistas a líderes políticos en Informativos Telecinco, o el de Arévalo-Salinas et al. (2021), que indaga sobre la inserción de imágenes o música en el telediario público, además de otras decisiones (fuentes usadas, duración de la noticia...).

Investigaciones futuras pueden plantear complementos metodológicos que incluyan estos otros ítems citados o buscar simplemente una actualización de lo aquí descrito. En todo caso, es posible sacar más provecho del buscador Verba afinando el método para que no se contabilicen los resultados que no son pertinentes por no estar relacionados con los líderes y temas políticos de que se trate. Una posibilidad sería pulirlos uno a uno cuando el número de menciones no sobrepase determinado umbral y tomar una muestra cuando sí se rebase.

\section{REFERENCIAS}

Alonso González, M. y García Orta, M.J. (7 - 8 de noviembre de 2016) Ciudadanos y Web 2.0: las nuevas formas de participación apuestan por la transparencia en la gestión [ponencia] VIII Congreso Internacional de Ciberperiodismo: El impacto de las audiencias en los perfiles profesionales y los contenidos (30-46). Universidad del País Vasco. Bilbao, España. https://addi.ehu.es/handle/10810/23577

Arévalo-Salinas, A.I., Al-Najjar Trujillo, T. y Aidar-Abib, T. (2021). La cobertura informativa de la inmigración en Televisión Española. El caso del barco Aquarius. Estudios sobre el Mensaje Periodístico, 271), 13-25. https://dx.doi.org/10.5209/esmp.73744

Bernete, F. (2013). Análisis de contenido (cuantitativo y cualitativo). En Marín, A. L. y Noboa, A. (eds.), Conocer lo social: estrategias y técnicas de construcción y 
análisis de datos, 221-262. Madrid. https://eprints.ucm.es/id/eprint/24160/1/Bernete\%20(2013b).pdf

Carsí Sánchez, I. (2016). Fundación Civio y Poletika; las redes sociales como herramientas de monitorización política. [TFG en la Universitat Jaume I]. Repositori Universitat Jaume I. http://repositori.uji.es/xmlui/handle/10234/163896

Casero-Ripollés, A. y López-Meri, A. (2015). Redes sociales, periodismo de datos y democracia monitorizada. En Freire, F.C. y Araújo, J.R. (eds.), Las redes sociales digitales en el ecosistema mediático. 96-113. Cuadernos Artesanos de Comunicación, 92. Tenerife: SLCS.

Capoano, E. (2018). Innovación en medios independientes digitales: casos en Brasil y España. Mediatika, 16, 73-90.

CIS (2021). Estudio 3330, barómetro de julio de 2021. Centro de Investigaciones Sociológicas. http://www.cis.es/cis/export/sites/default/Archivos/Marginales/3320 3339/3330/es3330mar.pdf

Consejo Audiovisual de Andalucía (2013, 5 de febrero). La excepción audiovisual española, único país de la UE sin un consejo audiovisual. Blog del Consejo Audiovisual de Andalucía. https://blogcaa.com/2013/02/05/la-excepcionaudiovisual-espanola/

Estevez, J.; Dominguez, J.J. y Graña, M. (2020). Relationship between the visibility of political leaders during campaign and the outcome in general elections. A case study for Spain. CoRR, february 2020. https://arxiv.org/abs/2002.07768

Ferreras Rodríguez, E.M. (2016). El periodismo de Datos en España. Estudios sobre el Mensaje Periodístico, 22(1), 255-272. Madrid, Ediciones Complutense. https://doi.org/10.5209/rev ESMP.2016.v22.n1.52594

Matarín Rodríguez-Peral, E. (2020). Inmigración y COVID-19: Análisis de los informativos en televisión durante la pandemia. methaodos.revista de ciencias sociales, 8 (2), 288-304. http://dx.doi.org/10.17502/mrcs.v8i2.412

MacKuen, M. B. (1981). Social communication and the mass policy agenda. En M.B. Mackuen, S.L. Coombs y G.M. Britan (eds.), More Than News: Media Power in Public Affairs 19-144. Newbury Park, CA: Sage.

Sánchez Calero, M. y Mancinas-Chávez, R. (2017). Periodismo con datos no es igual que Periodismo de datos. TecCom Studies, 8, 53-69. http://www.teccomstudies.com/index.php?journal=teccomstudies\&page=article\&o $\mathrm{p}=$ view\&path[] $=49$ 
Sánchez Castillo, S. (2018). Audiovisual Politeness in TV Political Interviews. $\begin{array}{llll}\text { Communication } \& \text { Society, } & \text { 31(2), }\end{array}$ https://dadun.unav.edu/handle/10171/55761

Silver, N. (2015, 15 de diciembre). Trump Boom Or Trump Bubble? Don't expect his numbers to fade - until his media coverage do. FiveThirtyEight. https://fivethirtyeight.com/features/trump-boom-or-trump-bubble/

Stray, J. (2016, 11 de enero). How much influence does the media really have over elections? Digging into the data. Nieman. https://www.niemanlab.org/2016/01/how-much-influence-does-the-media-reallyhave-over-elections-digging-into-the-data/

Teso, G. (2014). Metodología aplicada para el análisis de las noticias televisivas sobre cambio climático desde perspectivas cruzadas. En Arto, M., Barba, M., Rodrigues, F. M. y Meira, P. A. (eds.), Investigar o cambio climático na interface entre a cultura cientifica e a cultura común. https://cutt.ly/Kf3Z29S

Valero-Pastor, J.M. y Carvajal, M. (2019). "Transferencia de conocimiento para la innovación en las organizaciones periodísticas. Estudio de casos españoles". Revista Latina de Comunicación Social, 74, 1154-1172. 10.4185/RLCS-2019-1376

Vicente García, M. (2020). A táboa periódica, a química, e os medios de comunicación. Boletín das Ciencias, 90, 121-128.

Watt, J.H.; Mazza, M. and Snyder, L. (1993). Agenda-setting effects of television news coverage and the effects decay curve. Communication Research, 20(3), 408$435 . \quad$ https://www.semanticscholar.org/paper/Agenda-Setting-Effects-ofTelevision-News-Coverage-WattMazza/845fad6a356492064afb789abe644f0ac54c9a05?p2df

\section{AUTOR/ES:}

\section{Noel Bandera López}

Investigador predoctoral en el Instituto de Derechos Humanos de la Universitat de València, beneficiario de la ayuda FPU del Gobierno de España para la Formación de Profesorado Universitario, con 3 licenciaturas y grados (Derecho, Ciencias Políticas y de la Administración y Sociología) y 2 másteres (Filosofía contemporánea y Comunicación, cultura, sociedad y política) en la Universidad de Granada y en la Universidad Nacional de Educación a Distancia. Impulsor del proyecto Accountable para la evaluación del cumplimiento de los programas electorales, su tesis doctoral es "Materialización de valores democráticos en España en el contexto de las elecciones europeas 2019", dirigida por Roberto Viciano Pastor y a defender en 2022. noel.bandera-lopez@uv.es

Orcid ID: https://orcid.org/0000-0001-7142-0174

Google Scholar: https://scholar.google.com/citations?user=t2Ux 2AAAAAJ\&hl=es 